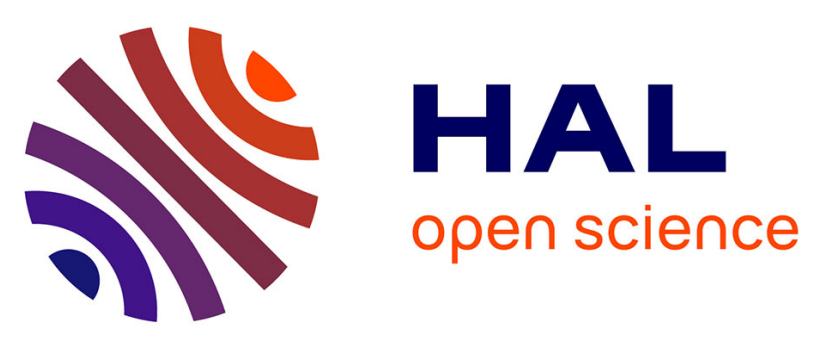

\title{
Fatigue and Post-Fatigue tensile behaviour of Non-Crimp stitched and unstitched Carbon/Epoxy composites
}

Valter Carvelli, Vanni Neri Tomaselli, Stepan V. Lomov, Ignaas Verpoest, Volker Witzel, Bjorn van den Broucke

\section{To cite this version:}

Valter Carvelli, Vanni Neri Tomaselli, Stepan V. Lomov, Ignaas Verpoest, Volker Witzel, et al.. Fatigue and Post-Fatigue tensile behaviour of Non-Crimp stitched and unstitched Carbon/Epoxy composites. Composites Science and Technology, 2010, 70 (15), pp.2216. 10.1016/j.compscitech.2010.09.004 . hal-00690070

\section{HAL Id: hal-00690070 https://hal.science/hal-00690070}

Submitted on 21 Apr 2012

HAL is a multi-disciplinary open access archive for the deposit and dissemination of scientific research documents, whether they are published or not. The documents may come from teaching and research institutions in France or abroad, or from public or private research centers.
L'archive ouverte pluridisciplinaire HAL, est destinée au dépôt et à la diffusion de documents scientifiques de niveau recherche, publiés ou non, émanant des établissements d'enseignement et de recherche français ou étrangers, des laboratoires publics ou privés. 


\section{Accepted Manuscript}

Fatigue and Post-Fatigue tensile behaviour of Non-Crimp stitched and unstitched Carbon/Epoxy composites

Valter Carvelli, Vanni Neri Tomaselli, Stepan V. Lomov, Ignaas Verpoest, Volker Witzel, Bjorn Van den Broucke

PII:

S0266-3538(10)00349-0

DOI:

10.1016/j.compscitech.2010.09.004

Reference:

CSTE 4807

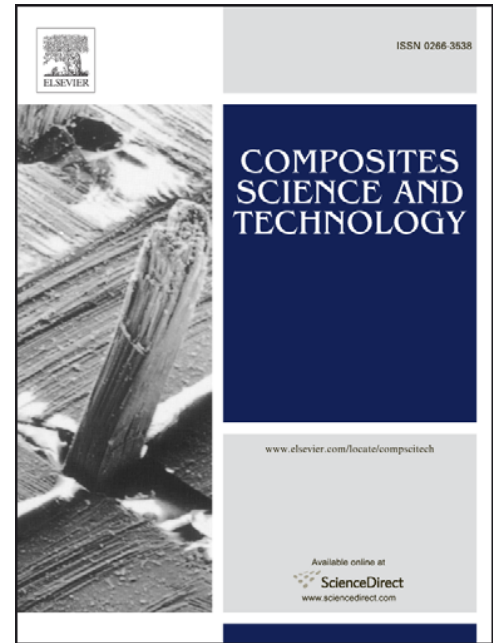

To appear in:

Composites Science and Technology

Received Date:

22 February 2010

Revised Date:

23 July 2010

Accepted Date:

9 September 2010

Please cite this article as: Carvelli, V., Tomaselli, V.N., Lomov, S.V., Verpoest, I., Witzel, V., Van den Broucke, B., Fatigue and Post-Fatigue tensile behaviour of Non-Crimp stitched and unstitched Carbon/Epoxy composites, Composites Science and Technology (2010), doi: 10.1016/j.compscitech.2010.09.004

This is a PDF file of an unedited manuscript that has been accepted for publication. As a service to our customers we are providing this early version of the manuscript. The manuscript will undergo copyediting, typesetting, and review of the resulting proof before it is published in its final form. Please note that during the production process errors may be discovered which could affect the content, and all legal disclaimers that apply to the journal pertain. 


\title{
FATIGUE AND POST-FATIGUE TENSILE BEHAVIOUR OF NON-CRIMP STITCHED AND UNSTITCHED CARBON/EPOXY COMPOSITES
}

\author{
Valter Carvelli ${ }^{* 1}$, Vanni Neri Tomaselli ${ }^{1}$, Stepan V. Lomov ${ }^{2}$, Ignaas Verpoest ${ }^{2}$, \\ Volker Witzel ${ }^{3}$, Bjorn Van den Broucke ${ }^{4}$ \\ ${ }^{1}$ Department of Structural Engineering, Politecnico di Milano \\ Piazza Leonardo da Vinci 32, 20133 Milano (Italy) \\ ${ }^{2}$ Department of Metallurgy and Materials Engineering, Katholieke Universiteit Leuven \\ Kasteelpark Arenberg, 44, B-3001, Leuven, Belgium \\ ${ }^{3}$ IFB - Institut für Flugzeugbau, Universität Stuttgart, Germany \\ ${ }^{4}$ EADS Innovation Works, Munich, Germany
}

\section{ABSTRACT}

An experimental study is described in this paper dealing with the tensile-tensile fatigue and the quasistatic post-fatigue tensile behavior of a structurally stitched multi-ply carbon composite and the unstitched counterpart. The influence of the stitching on the fatigue life and on the residual post-fatigue quasi-static properties in two principal direction is investigated. The fatigue behavior of both composites is represented by Wöhler-like diagrams. The damage imparted during fatigue is studied by X-ray analyses. The residual mechanical properties of the fatigued composites after different number of cycles are compared in term of stiffness and strength. The post-fatigue quasi-static tensile tests include acoustic emission (AE) registration and full-field surface strain mapping (SM) to investigate the damage onset and

\footnotetext{
* Corresponding author:

tel.: +390223994354

fax: +390223994369

e-mail: valter.carvelli@polimi.it
} 
development. The main conclusions of the experimental work are: the fatigue life is improved in the direction of the structural stitching and is reduced in the orthogonal direction; for the considered cyclic stress level the post-fatigue reduction of the mechanical properties is limited by the structural stitching.

Keywords: (A) Laminate, (B) Fatigue, Mechanical Properties.

\section{INTRODUCTION}

Laminate composites have a broad range of application in several industrial fields (aircraft, marine, automobile, civil infrastructure, etc.) [1]. Their main drawback are the reduced out of plane mechanical properties. Among the techniques to increase the through-thickness properties, in the last decades, stitching of multi-ply preforms and of occasionally prepreg laminates attracted a large interest [2, 3]. The stitching benefits are the improvement of: delamination resistance, impact damage tolerance and out-ofplane stiffness of the laminate $[4,5]$. Other attractive benefits of the stitching are the robotically controlled multi-needle sewing machines and the cost-effective joining of multi-layer preforms which improve the ease of handling prior to liquid moulding [5].

The interest in stitching technologies for the reinforcement of polymer matrix composites led to a considerable number of studies devoted to the influence of the stitching on the mechanical properties of the laminates (see e.g. the review papers $[3,4,5,6]$ ). Some conclusions, in the mentioned review papers, on the large amount of experimental data appeared in the literature suggest:

- a benefit of the stitching is an improvement of the delamination resistance increasing the interlaminar fracture toughness under mode I and II loading conditions [4];

stitching improves the impact resistance and the post-impact mechanical properties [1];

the stiffness and strength of laminates loaded in quasi-static tension can be unaffected, increased or more common reduced by the stitching $[6,7]$;

- the influence of stitching on fatigue life of laminates was examined mainly under cyclic compression loads [1] and only few study appeared for tensile fatigue (see e.g. [7, 8, 9] for CFRP and $[10,11]$ for GFRP). 
Despite the knowledge of the results presented in literature, a deep understanding of the fatigue endurance of stitched composite is still request because of their potential application in structural elements subject to long-term fluctuating loads, especially under tension [6].

The present work aims to provide a contribution to understanding of tensile fatigue and post-fatigue behavior of a structurally stitched multi-ply carbon composite. To assess the influence of the structural stitching on the mechanical response of the stitched composite the experimental data are compared to the ones of the unstitched carbon composite counterpart. The term 'structural' means that the stitching yarn does not only consolidate the plies (as the non-structural one does) but forms also a through the thickness reinforcement. The quasi-static mechanical response of the considered stitched carbon composite, produced in a different batch, were experimentally investigated in [12].

The first part of the paper presents the characteristics of the two composites and the description of the experimental techniques applied. In the second part, the tensile-tensile fatigue life is presented and compared by Wöhler-like diagrams. Pictures obtained by X-ray device are used to investigate the damage patterns produced during fatigue after different number of cycles for a stress amplitude. The last part of the paper is dedicated to the post-fatigue residual mechanical properties of composites undergone different number of cycles. During the post-fatigue quasi-static tensile tests, the techniques described in detail in [13] (acoustic emission registrations and optic full-field surface strain measurements) were used to investigate the damage onset and development.

\section{MATERIALS}

The stitched and unstitched preforms (see Figure 1 and Figure 2) are laminated using two Seartex ${ }^{\circledR}$ non-crimp fabrics (NCFs) made of Tenax HTS carbon fibres:

the fabric with the plies construction $+45^{\circ} /-45^{\circ}$, areal weight of the plies of $267 \mathrm{~g} / \mathrm{m}^{2}$ (total areal weight of the fabric of $540 \mathrm{~g} / \mathrm{m}^{2}$ );

- the $0^{\circ} / 90^{\circ}$ fabric with areal weight of the plies of $283 / 267 \mathrm{~g} / \mathrm{m}^{2}$ (total areal weight of the fabric $\left.556 \mathrm{~g} / \mathrm{m}^{2}\right)$. 
Each NCF has a polyester sewing thread $\left(8.3\right.$ tex, $2.6 \times 5 \mathrm{~mm}$ tricot + chain knitting pattern, $\left.6 \mathrm{~g} / \mathrm{m}^{2}\right)$ that knits together the carbon plies. The fabrics are stacked to form a symmetric laminate [45/$45 / 0 / 90 / 45 /-45]_{\mathrm{S}}$ and has a total thickness of about $4.2 \mathrm{~mm}$ before impregnation. $90^{\circ}$ direction corresponds to the non-structural sewing direction (see Figure 2).

The structurally stitched composite has a 5 x $5 \mathrm{~mm}$ square piercing pattern made with a $1 \mathrm{~K}$ carbon rowing and tufting method (KL RS 522 stitching head mounted on a KUKA-robot). The stitching direction coincides with $0^{\circ}$. Typical appearance of the stitched preforms is shown in Figure 1 . It is shown [12] that the knitting device for the stitching process produces openings in the composite and these openings are naturally oriented along the global fibres orientation in the ply. Characteristics of the reinforcement, stitching yarn and non-structural sewing thread are listed in Table 1.

The impregnation of unstitched and stitched preforms is obtained through VAP (Vacuum Assisted Process) using RTM-6 epoxy resin $\left(\right.$ HexFlow $^{\circledR}-$ Hexcel $\left.^{\circledR}\right)$. The final thickness of the cured laminates of $3.2 \div 3.5 \mathrm{~mm}$ shows a significant densification in comparison with the dry state. The volume fraction $\left(V_{f}\right)$ was $\approx 54 \%$.

\section{EXPERIMENTAL SETUP}

The tensile fatigue and the tensile quasi-static post-fatigue tests were performed using prismatic specimens having width $25 \mathrm{~mm}$ and total length $250 \mathrm{~mm}$. Aluminium tabs $(1.5 \mathrm{~mm}$ thick) glued in the grip zones gave a free length of $150 \mathrm{~mm}$. Each specimen was preliminary checked by C-scan device (HFUS 2000 - Ingenieurbüro Dr. Hillger) to detected defects or damage imparted during the production of the laminates and the preparation of the specimens.

\subsection{Tensile-tensile fatigue tests}

Two hydraulic MTS testing machines were adopted for fatigue investigation. Tests were performed under constant stress amplitude, sinusoidal wave-form tensile-tensile loading and assuming the ratio $\mathrm{R}=$ 0.1 (ratio of the minimum $\sigma_{\min }$ to the maximum $\sigma_{\max }$ stress in the cycle). The stress was evaluated by the specimen cross-section area averaged from three measurements. In the direction $0^{\circ}$ and $90^{\circ}$ of both 
composites, four different maximum stress levels were considered (see Table 2) in order to have a complete characterization, from values close the static strength (see [12]), to the stress level which did not lead to a complete failure before 2 million cycles. Complete failure means separation in two parts of the specimen during cyclic loading. To avoid the influence of tabs zones and grips pressure, a cyclic test was considered "valid" if the specimen broke at a distance greater than $2 \mathrm{~cm}$ from the tabs. At least three valid specimens were tested for each considered stress level. The loading frequency was in the range $4 \div 8 \mathrm{~Hz}$ according to the applied maximum stress, as detailed in Table 2.

\subsection{Quasi static post-fatigue tensile tests}

The post-fatigue experimental activity included quasi-static tensile loading up to failure with acoustic emission (AE) registration, full-field surface strain mapping (SM). The specimens dedicated to postfatigue tractions were scanned by X-ray to assess the damage imparted during the cyclic test (see section 6). The post-fatigue tensile tests were performed using an INSTRON 4505 machine setting the crosshead speed of $2 \mathrm{~mm} / \mathrm{min}$. Each specimen was equipped with two acoustic emission (AE) sensors placed at the boundaries of the gauge length region. The energy of AE events registered by the AE system (AMSY-5, Vallen Systems GmbH, see details in [13]) and the associated loading level provide the cumulative energy for each stress level. Signals occurred outside the sensors are filtered out by the AE system by means of a suitable calibration procedure. The processing of the acoustic emission data allows to determine stress levels corresponding to characteristic damage thresholds (see section 7.2).

An optical extensometer was adopted to have the true values of strain components. The employed system measures the surface strain in the centre of the specimen (about $30 \mathrm{~mm}$ long gauge region) by means of the correlation of subsequent digital images taken during loading. The strain maps (SM) were obtained by the Vic2D software (LIMESS Messtechnik und Software GmbH); parameters of the strain mapping device are reported in [13]. 


\section{FATIGUE RESULTS}

Fatigue tests can be split in two different groups: fatigue until failure or 2 million cycles to generate a Wöhler-like diagram and a series of fatigue tests with fixed stress level stopped to different number of cycles. The second group of specimens were scanned by X-Ray after fatigue to detect the damage imparted and then tested under quasi-static load to determine the degradation of the mechanical properties increasing the number of cycles.

\subsection{Qualitative damage considerations}

The usual damage pattern of the specimens after 2 million cycles (no failure) reveals an extremely diffused delamination on the unstitched composite and limited delamination on the stitched counterpart, see Figure 3. The failure mechanism is also qualitatively different when complete failure was obtained in the cyclic tests (see Figure 4); the layers of the stitched laminate remains rather in contact, while the layers in the unstitched one had complete separation. Both in $0^{\circ}$ and $90^{\circ}$ loading direction, cracks appear in the external layers after few thousands cycles with higher stress levels: $350 \mathrm{MPa}$ for unstitched and 400 MPa for stitched composite. The structural stitching prevents macro delaminations in particular for $90^{\circ}$ loading direction.

The development of the damage during the cyclic tests could be studied comparing the variation of the shape of fatigue stress-displacement cycles (further called "cycle curve") and of the maximum and minimum displacement vs. the number of cycles. The displacement is in the loading direction as recorded by the tensile device. Considering tests with maximum stress $200 \mathrm{MPa}$ and $0^{\circ}$ load direction, Figure 5 shows how the damage develops differently in the stitched and unstitched composites. Most of the damage occurs within 1 million cycles for the unstitched specimens (see Figure 5a). The slope of the cycle curve, segment passing through the points of maximum and minimum stress (called "cycle slope"), continuously decreases up to one million cycles (reduction of the cycle slope of $\approx 34 \%$ for specimen in Figure 5a). Above one million cycles, the slope remains nearly constant (cycle slope decreases of $\approx 5 \%$ in the range $1 \div 2$ million cycles). These statements are confirmed also by observing the evolution of the maximum and minimum displacements for increasing number of cycles (see Figure 5a). The stitched laminate shows (see Figure $5 \mathrm{~b}$ ) the maximum reduction of the cycle slope within $250 \mathrm{k}$ cycles $(\approx 12 \%$ for 
sample in Figure $5 \mathrm{~b})$, a considerable lower reduction in the range $250 \mathrm{k} \div$ one million cycles $(\approx 5 \%)$ and nearly stable shape of the cycles above one million cycles (reduction of the cycle slope of $\approx 2 \%$ between 1 and 2 million cycles). The above analysis confirm a different damage initiation and development behaviour of the two considered composites.

\subsection{Wöhler-like diagrams}

In Figure 6, the valid tests of the unstitched composite loaded in $0^{\circ}$ and $90^{\circ}$ are collected to depict a Wöhler-like diagram, i.e. maximum stress in the cycle $\left(\sigma_{\max }\right)$ vs. the number of cycles to failure N. The results of the valid tests for the stitched composite in $0^{\circ}$ and $90^{\circ}$ direction loading are shown in Figure 7 , respectively. In each diagram the average static tensile strength, obtained in a previous work for a different production batch [12], is also indicated as corresponding to the number of cycles $\mathrm{N}=1$.

A summary and comparison of average number of cycles to failure for the stress levels considered, for each composite and loading direction is given in Figure 8.

The stitched composite shows a longer fatigue life when loaded in $0^{\circ}$ direction than in $90^{\circ}$, for any stress level considered. The opposite behaviour is observed for the unstitched composite, i.e. loading in $90^{\circ}$ direction provides an higher average number of cycles to failure with respect to $0^{\circ}$ direction for any considered stress level.

The stitching has a positive effect in term of fatigue life when the load is applied along the $0^{\circ}$ fibres i.e. the stitching direction (see Figure 6a, Figure 7a). For the stress levels in Figure 8a,b, the average fatigue life of stitched composite is $140 \%$ and $322 \%$ higher for maximum stress $240 \mathrm{MPa}$ and $320 \mathrm{MPa}$, respectively, with respect to the unstitched counterpart. On the other hand, the stitching has a negative effect on the tensile fatigue life when load is applied in $90^{\circ}$ direction, i.e. orthogonal to the stitching direction (see Figure $6 \mathrm{~b}$ and Figure $7 \mathrm{~b}$ ). In this case, the reduction of the average fatigue life (see Figure $8 \mathrm{a}, \mathrm{b})$, is $52 \%$ and $73 \%$ for $240 \mathrm{MPa}$ and $320 \mathrm{MPa}$, respectively. All these differences are statistically significant at least at $95 \%$ confidence level.

The above mentioned results show: 
(1) The unstitched composite has the best fatigue performance if loaded in the direction of the polyester sewing thread (non-structural), i.e. $90^{\circ}$, while has reduced fatigue life when loaded orthogonally to this direction (i.e. $0^{\circ}$ ).

(2) The structural carbon stitching provides an improvement of the fatigue performance when the tensile cyclic load is applied in the carbon stitching direction $\left(0^{\circ}\right.$ in the present study), on the contrary the fatigue life decreases when loading is orthogonal to the structural stitching direction.

\section{POST-FATIGUE X-RAY DAMAGE ANALYSIS}

The damage imparted during fatigue tests was investigated using an X-ray device. In particular, the damage analysis was focused on specimens fatigued up to three fixed number of cycles $(1 \mathrm{k}, 10 \mathrm{k}$, and $100 \mathrm{k}$ ) (' $\mathrm{k}$ ' means thousand) with maximum stress of $240 \mathrm{MPa}$.

In order to make the cracks and other damages visible, the specimens were maintained under the effect of a reactant for 12 hours. The reactant was a $99 \%$ diiodomethane solution. Using the Micro Focus Computer Tomography AEA Tomohawk system, 2D images of the specimens were produced. The specimens were irradiated with a Phillips ${ }^{\circledR}$ HOMX 161 X-ray source setting: voltage $89 \mathrm{kV}$, current $0.38 \mathrm{~mA}$ and iris position $91.9 \%$.

Typical appearance of unstitched specimens is shown in Figure 9 and Figure 10: cracks in $\pm 45^{\circ}$ directions are evident and mostly affecting the external layers. Density of cracks increases with the number of cycles and after 100k cycles the unstitched composite shows large delamination zones (dark/black areas in Figure 9c). The delamination is mainly concentrated at the interface between the $\pm 45^{\circ}$ external layers and the rest of the lay-up. Debonding and cracks are also visible in the central part of the cross-section (Figure 10).

Figure 11 and Figure 12 show stitched specimens after fatigue. A large density of cracks appear in $\pm 45^{\circ}$ direction, and as expected the density increases with increasing number of cycles. After 10k cycles marked openings appear on the specimen according to the stitching pattern. The damage observation in the cross-section shows the stitching effect in reducing the delamination. Some delaminations appear after 100k cycles (Figure 12c) but extremely reduced in comparison to the unstitched composite (Figure 10c). 


\section{POST-FATIGUE QUASI-STATIC TENSILE TEST RESULTS}

The influence of the fatigue loading on the residual mechanical properties was measured by quasistatic tensile tests of specimens fatigued with maximum stress $240 \mathrm{MPa}$ after different number of cycles $(1 \mathrm{k}, 10 \mathrm{k}$ and $100 \mathrm{k})$. The post-fatigue tensile tests were equipped with the strain mapping device and AE sensors. The quasi-static tensile tests of unstitched composite fatigued in $90^{\circ}$ direction after $100 \mathrm{k}$ cycles could not be performed due to the elevate damage imparted during the fatigue tests.

\subsection{Residual Mechanical Properties}

The residual mechanical properties of the two composites in both loading direction are summarized in the histograms of Figure 13 in term of stiffness (elastic modulus) and strength (ultimate stress). For each composite and loading direction, one specimen has been tested for each pre-defined number of cycles. The comparison of the obtained mechanical properties (Figure 13) provides only a trend of the fatigue influence on the residual mechanical properties, but cannot be considered exhaustive due to the limited number of specimens. A larger set of experimental data will be collect in future work.

The residual elastic moduli in Figure 13a show an invariance of the stiffness up to 10k cycles, while a significant dropping is observed after 100k cycles, especially for the unstitched composite in $0^{\circ}$ direction (reduction of $30 \%$ with respect to the value for $1 \mathrm{k}$ cycles). Only the stitched composite tested in $90^{\circ}$ direction maintains the stiffness even after $100 \mathrm{k}$ cycles, while in $0^{\circ}$ direction a reduction of $13 \%$ was recorded with respect to the modulus after $1 \mathrm{k}$ cycles.

The comparison of average ultimate stress (see Figure 13b) shows rather stable values of the strength after $10 \mathrm{k}$ cycles, a maximum reduction of $9 \%$ was recorded for the unstitched composite in $90^{\circ}$ direction. A significant drop of $40 \%$ is notable after $100 \mathrm{k}$ cycles for the unstitched composite in $0^{\circ}$, while the stitched showed only a reduction, with respect to the strength after $1 \mathrm{k}$ cycles, of $11 \%$ and $6 \%$ in $0^{\circ}$ and $90^{\circ}$ direction, respectively.

It must be highlighted that this comparison does not use the quasi-static data in [12] (which were measured on different batch), but is fully related to the composites in the present study. 


\subsection{Strain maps and Acoustic Emissions recordings}

The optical extensometer provides maps of the strain components on the external surface of the specimen. The picture frame $(25 \mathrm{~mm}$ x $30 \mathrm{~mm})$, placed in the centre of the specimen, was painted with spackle pattern for digital image correlation and was dedicated to the study of the strain distribution. The stitched composite, after 10k cycles, provide the two maps of the strain component in the load direction in Figure 14 ((a) loading in $0^{\circ}$ direction and (b) in $90^{\circ}$ ) for a stress level of $220 \mathrm{MPa}$. In Figure 14, both strain maps show a regular pattern of concentrations in the stitching points, i.e. the zones where the damage starts to develop. It is reminded that the optical extensometer device takes pictures of the external layers $\left( \pm 45^{\circ}\right)$.

The acoustic emission (AE) equipment records acoustic events and provides the cumulative energy. In Figure 15 and Figure 16, typical AE diagrams are depicted for a specimen of each composite and for each loading direction considered. The processing of these results allowed to determine: the AE Threshold Stress (AETS) $\sigma_{\min }$, above which relatively low energy acoustic events start to occur; the First Damage Threshold Stress (FDTS) $\sigma_{1}$ at the first increase of the slope of the cumulative AE energy curve; the Second Damage Threshold Stress (SDTS) $\sigma_{2}$ at the second "knee" on the AE cumulative energy curve [12]. In Table 3 the value of average threshold $\sigma_{1}$ and $\sigma_{2}$ are collected for the specimens fatigued after different number of cycles. The graphs in Figure 15 and Figure 16 and the values of first damage threshold stress $\sigma_{1}$ in Table 3 show a significant amount of events recorded close to the maximum stress formerly set during fatigue tests (240 MPa), below this threshold the amount of noise is barely significant. The damage detected during quasi-static tensile tests in [12], below the stress level of $240 \mathrm{MPa}$, was not recorded in the present work because completely imparted during cyclic tests. The large part of the damage (AE events) appears in the present quasi-static tensile loading for stress levels above the maximum stress applied during fatigue. 


\section{CONCLUSIONS}

The experimental study, presented in this work, deals with the fatigue and the post-fatigue quasi-static tensile mechanical response of a structurally stitched multi-ply carbon composite and its equivalent unstitched counterpart. The mechanical response was investigated in two orthogonal directions and the main results are summarized in the following.

The fatigue tests showed:

- unstitched composite has the best performance in the direction of the non-structural polyester sewing $\left(90^{\circ}\right)$ and the worst in $0^{\circ}$, for each stress level considered;

- X-ray images of unstitched composite show, for the considered stress level, a diffuse delamination after the early stage of the cyclic tests (after 10k cycles) in both loading directions;

- structural stitching increase the fatigue life in the sewing direction $\left(0^{\circ}\right)$ and reduce the one in the direction orthogonal to the stitching $\left(90^{\circ}\right)$;

- fatigue life in $0^{\circ}$ direction of the stitched and in $90^{\circ}$ of the unstitched composite are similar.

The post-fatigue quasi-static tests demonstrate:

- unstitched composite shows invariance of the stiffness in the early stage of the cyclic loading (after 10k cycles), and a significant reduction after 100k cycles ;

- stitched composite tested in $90^{\circ}$ direction did not have a significant decrease of the stiffness even after 100k cycles;

- ultimate stress has stable values if unstitched composite is fatigued for $10 \mathrm{k}$ cycles in direction $0^{\circ}$, while has significant drop after 100k cycles ;

the influence of the cyclic loading on the ultimate stress of the stitched composite is considerable lower than on the unstitched counterpart.

\section{Acknowledgements}

The research reported here has been carried out in the framework of the Erasmus Master program of Vanni Neri Tomaselli in K.U. Leuven and Politecnico di Milano. The help of laboratory staff of the Department MTM - Bart Pelgrims, Kris van der Staey and Johan Vanhuist - is gratefully acknowledged 


\section{REFERENCES}

1. Tong L, Mouritz AP, Bannister MK. 3D Fibre Reinforced Polymer Composites, Elsevier, 2002.

2. Bogdanovich AE, Mohamed MH. Three-Dimensional Reinforcements for Composites. SAMPE Journal 2009; 45(6): 8-28.

3. Mouritz AP, Bannister MK, Falzon PJ, Leong KH. Review of applications for advanced threedimensional fibre textile composites. Composite Part A 1999; 30: 1445-1461.

4. Dransfield K, Baillie C, Mai YW. Improving the delamination resistance of CFRP by stitching a review. Composites Science and Technology 1994; 50: 305-317.

5. Mouritz AP, Leongb KH, Herszberg I. A review of the effect of stitching on the in-plane mechanical properties of fibre-reinforced polymer composites. Composite Part A 1997; 28: 979-991.

6. Mouritz AP, Cox BN. A mechanistic approach to the properties of stitched laminates. Composite Part A 2000; 31: 1-27.

7. Beier U, Fischer F, Sandler JKW, Altsta V, Weimer C, Buchs W. Mechanical performance of carbon fibre-reinforced composites based on stitched preforms, Composite Part A 2007; 38: 1655-1663.

8. Aymerich F, Priolo P, Sun CT. Static and fatigue behaviour of stitched graphite/epoxy composite laminates Composites Science and Technology 2003; 63: 907-917.

9. Vallons K, Mengmeng Zong, Lomov SV, Verpoest I. Carbon composites based on multi-axial multiply stitiche preforms - Part 6. Fatigue behaviour at low loads: Stiffness degradation and damage development. Composite Part A 2007; 38: 1633-1645.

10. Shah Khan MZ, Mouritz AP. Fatigue behaviour of stitched GRP laminates. Composites Science and Technology 1996; 56: 695-701.

11. Aono Y, Hirota K, Lee SH, Kuroiwa T, Takita K. Fatigue damage of GFRP laminates consisting of stitched unit layers. International Journal of Fatigue 2008; 30: 1720-1728. 
12. Koissin V, Kustermans J, Lomov SV, Verpoest I, Van Den Broucke B, Witzel V. Structurally Stitched NCF preforms: Quasi-static response. Composites Science and Technology 2009; 69: 27012710.

13. Lomov SV, Ivanov DS, Truong TC, Verpoest I, Baudry F, Vanden Bosche K, Xie H. Experimental methodology of study of damage initiation and development in textile composites in uniaxial tensile test. Composites Science and Technology 2008; 68: 2340-2349. 


\section{LIST OF FIGURE CAPTIONS}

Figure 1. (a) Face side and (b) back side of 5 x $5 \mathrm{~mm}$ structural stitched preform.

Figure 2. (a) Face side and (b) back side of unstitched preform.

Figure 3. Fatigue tests maximum stress $200 \mathrm{MPa}$, load direction 90o. Cross-section view of (a) unstitched and (b) stitched specimen after 2 million cycles.

Figure 4. Fatigue tests maximum stress $320 \mathrm{MPa}$, load direction 90o. Cross-section view of (a) unstitched and (b) stitched specimen after complete failure.

Figure 5. Cyclic tests load in $0^{\circ}$ direction, maximum stress $200 \mathrm{MPa}$. Some stress vs. displacement curves; maximum and minimum displacement vs. number of cycles. (a) unstitched and (b) stitched composite.

Figure 6. Maximum stress $\sigma \mu \alpha \xi$ vs. number of cycles to failure $\mathrm{N}$ for unstitched composite loaded in: (a) $0^{\circ}$ direction; (b) $90^{\circ}$ direction. (' $\rightarrow$ ' means no failure after 2 million cycles).

Figure 7. Maximum stress $\sigma \mu \alpha \xi$ vs. number of cycles to failure $\mathrm{N}$ for stitched composite loaded in: (a) $0^{\circ}$ direction; (b) $90^{\circ}$ direction. (' $\rightarrow$ ' means no failure after 2 million cycles).

Figure 8. Average number of cycles to failure for the applied maximum stress levels $( \pm$ means standard deviation).

Figure 9. Typical X-Ray of unstitched specimens after cyclic traction in $0^{\circ}$ direction, maximum stress 240 MPa. Front view of specimens stopped at: (a) $1 \mathrm{k}$; (b) $10 \mathrm{k}$ and (c) $100 \mathrm{k}$ cycles.

Figure 10. Typical X-Ray of unstitched specimens after cyclic traction in $0^{\circ}$ direction, maximum stress $240 \mathrm{MPa}$. Cross-section view of specimens stopped at: (a) 1k; (b) 10k and (c) 100k cycles.

Figure 11. Typical X-Ray of stitched specimens after cyclic traction in $0^{\circ}$ direction, maximum stress 240 $\mathrm{MPa}$. Front view of specimens stopped at: (a) 1k; (b) 10k and (c) 100k cycles.

Figure 12. Typical X-Ray of stitched specimens after cyclic traction in $0^{\circ}$ direction, maximum stress 240 MPa. Cross-section view of specimens stopped at: (a) $1 \mathrm{k}$; (b) $10 \mathrm{k}$ and (c) $100 \mathrm{k}$ cycles.

Figure 13. (a) elastic modulus and (b) ultimate stress of fatigued specimens (maximum stress $240 \mathrm{MPa}$ ) after different number of cycles.

Figure 14. Mapping of the strain component in the load direction, for stress level $\approx 220 \mathrm{MPa}$. Load direction is horizontal. Specimens of stitched composite in (a) $0 \mathrm{o}$ and (b) $90 \mathrm{o}$ direction after 10.000 cycles with maximum stress $240 \mathrm{MPa}$.

Figure 15. Unstitched composite: post-fatigue tensile test in $0^{\circ}$ direction after: (a) 1.000 cycles and (b) 10.000 cycles, maximum stress $240 \mathrm{MPa}$. Acoustic Emission events and cumulative energy ([a.u.] means [arbitrary unit]).

Figure 16. Stitched composite: post-fatigue tensile test in $0^{\circ}$ direction after: (a) 1.000 cycles and (b) 10.000 cycles, maximum stress $240 \mathrm{MPa}$. Acoustic Emission events and cumulative energy ([a.u.] means [arbitrary unit]).

\section{LIST OF TABLE CAPTIONS}

Table 1. Some properties of the components (data from Seartex ${ }^{\circledR}$ and Walker Wilhelm $\mathrm{GmbH}$ ).

Table 2. Stress levels and frequencies adopted in cyclic loading.

Table 3. Damage threshold $\sigma 1$ and $\sigma 2$ of fatigued specimens after different number of cycles and maximum stress $240 \mathrm{MPa}$. 


\section{ACCEPTED MANUSCRIPT}

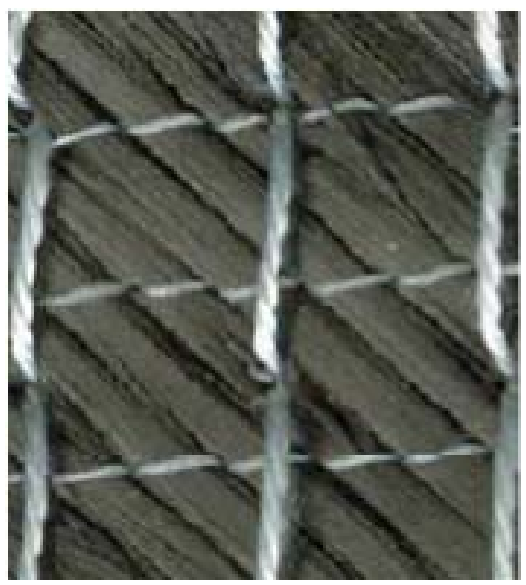

(a)

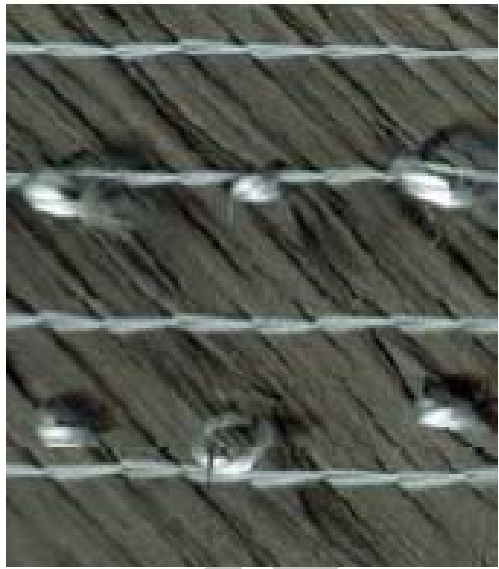

(b)

Figure 1. (a) Face side and (b) back side of 5 x $5 \mathrm{~mm}$ structural stitched preform.

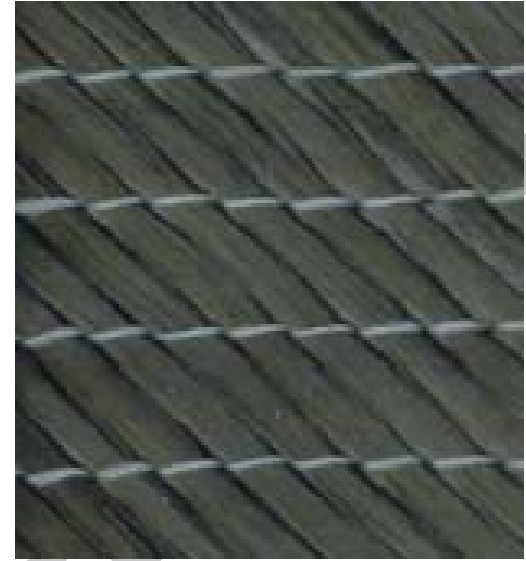

(a)

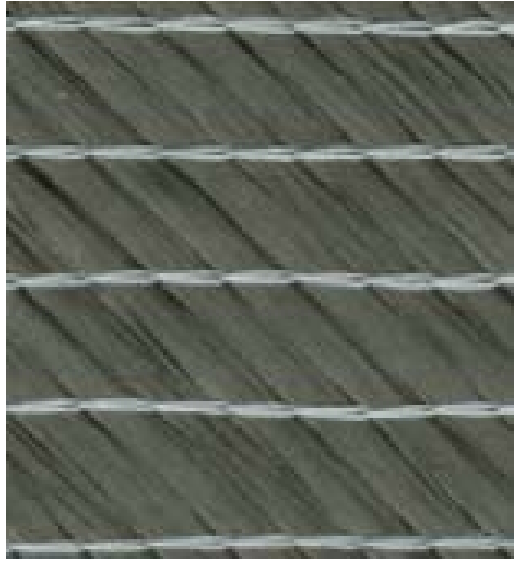

(b)

Figure 2. (a) Face side and (b) back side of unstitched preform. 


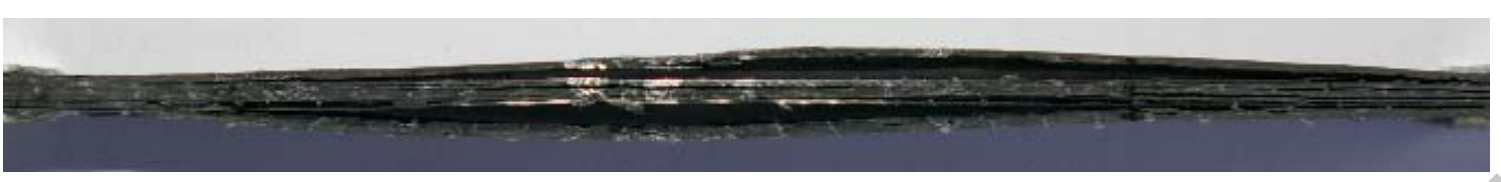

(a)

(b)

Figure 3. Fatigue tests maximum stress $200 \mathrm{MPa}$, load direction $90^{\circ}$. Cross-section view of (a) unstitched and (b) stitched specimen after 2 million cycles.

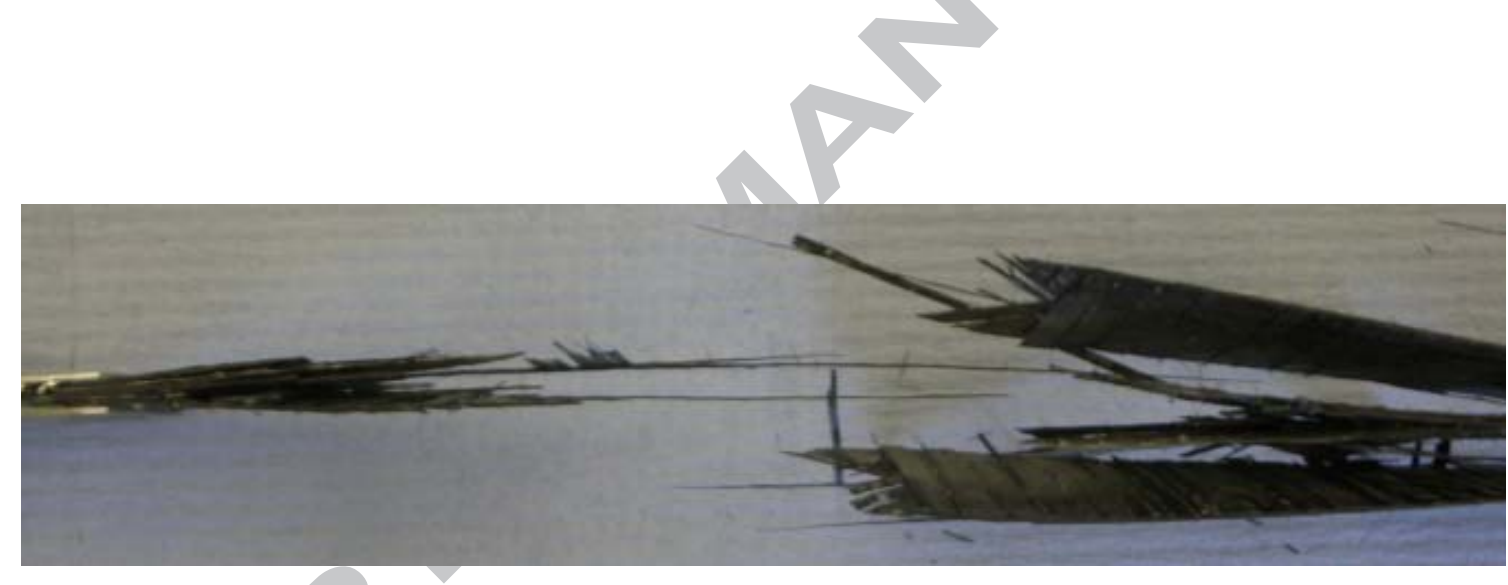

(a)

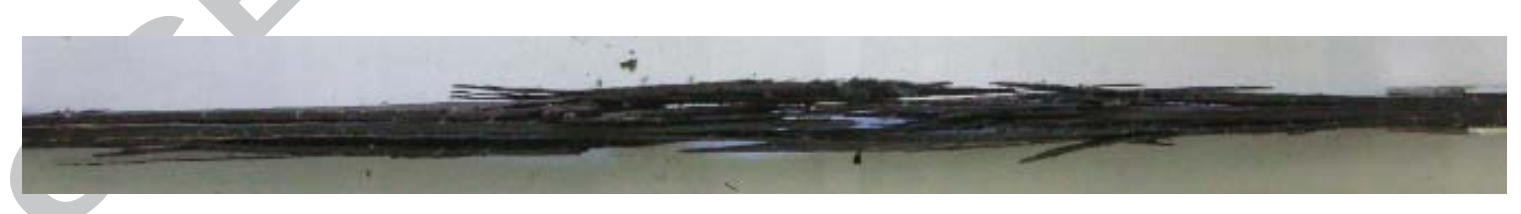

(b)

Figure 4. Fatigue tests maximum stress $320 \mathrm{MPa}$, load direction $90^{\circ}$. Cross-section view of (a) unstitched and (b) stitched specimen after complete failure. 


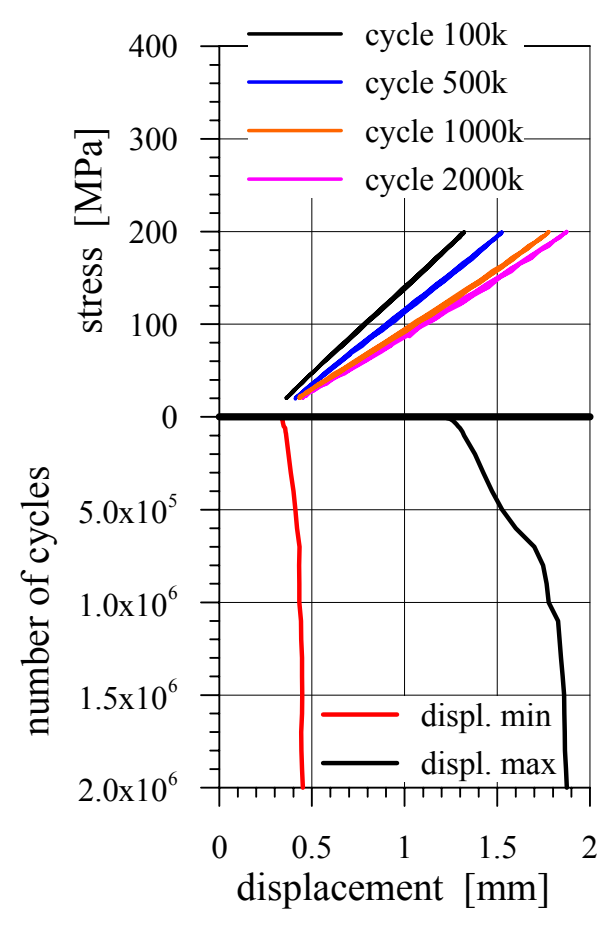

(a)

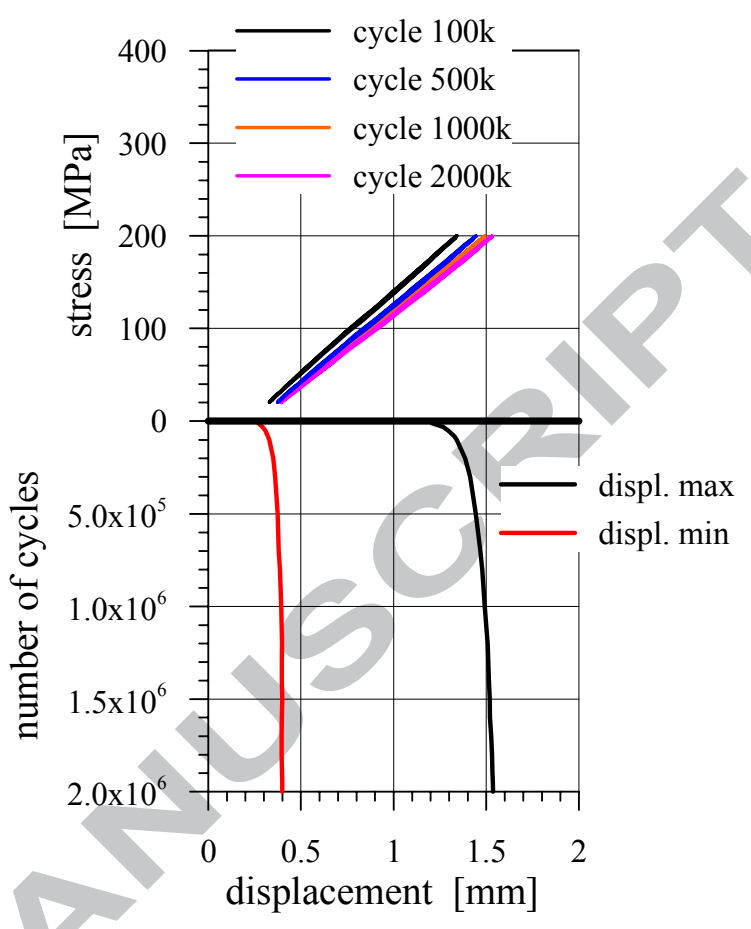

(b)

Figure 5. Cyclic tests load in $0^{\circ}$ direction, maximum stress 200 MPa. Some stress vs.

displacement curves; maximum and minimum displacement vs. number of cycles. (a) unstitched and (b) stitched composite.

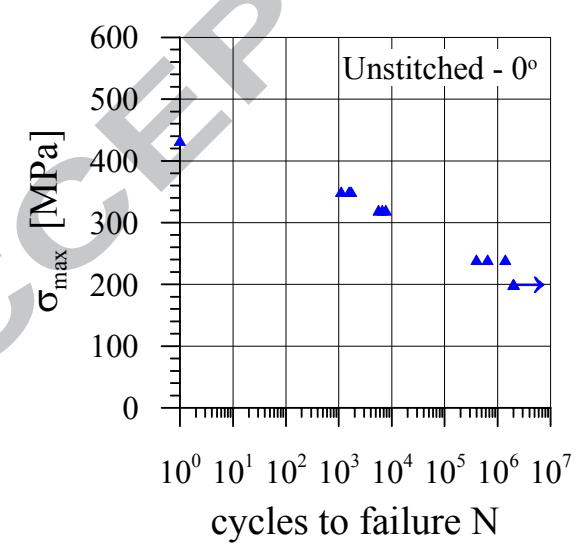

(a)

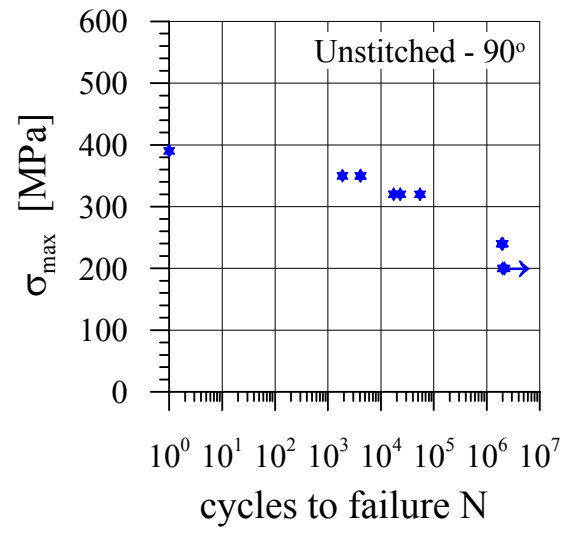

(b)

Figure 6. Maximum stress $\sigma_{\max }$ vs. number of cycles to failure $\mathrm{N}$ for unstitched composite loaded in: (a) $0^{\circ}$ direction; (b) $90^{\circ}$ direction. ( ${ }^{\rightarrow} \rightarrow$ ' means no failure after 2 million cycles). 


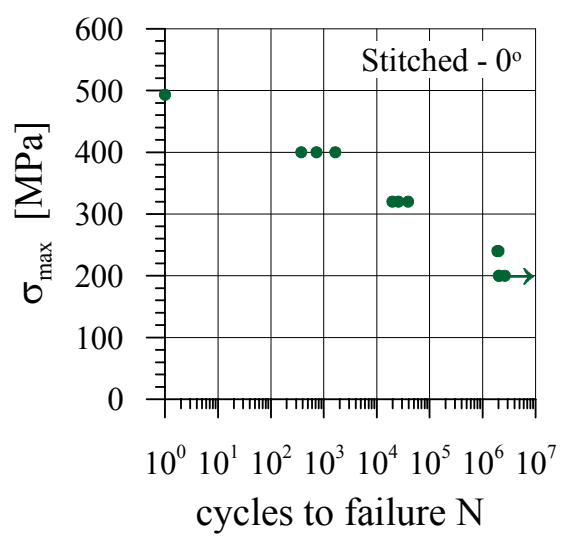

(a)

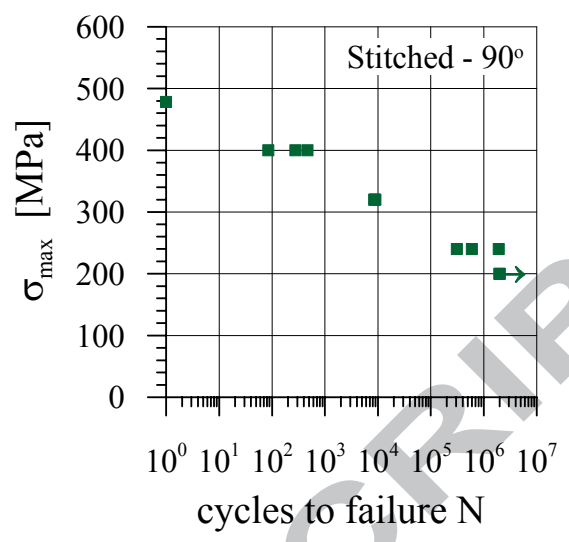

(b)

Figure 7. Maximum stress $\sigma_{\max }$ vs. number of cycles to failure $\mathbf{N}$ for stitched composite loaded in: (a) $0^{\circ}$ direction; (b) $90^{\circ}$ direction. (' $\rightarrow$ ' means no failure after 2 million cycles).

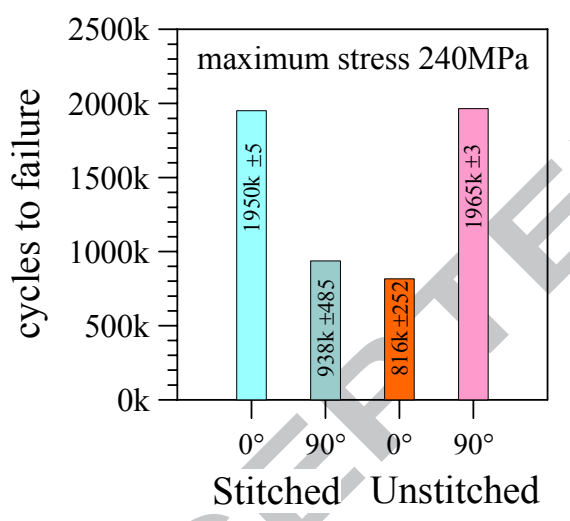

(a)

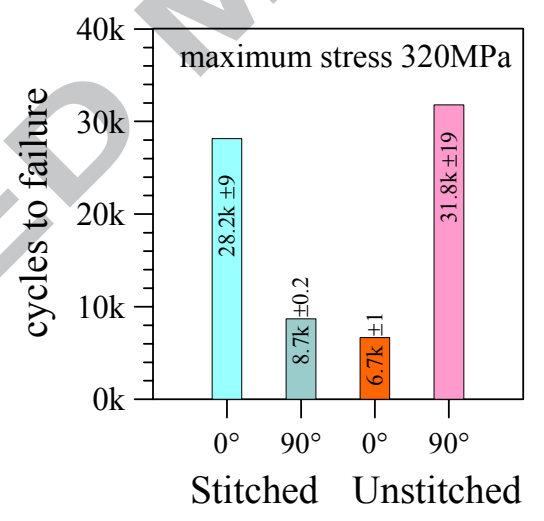

(b)

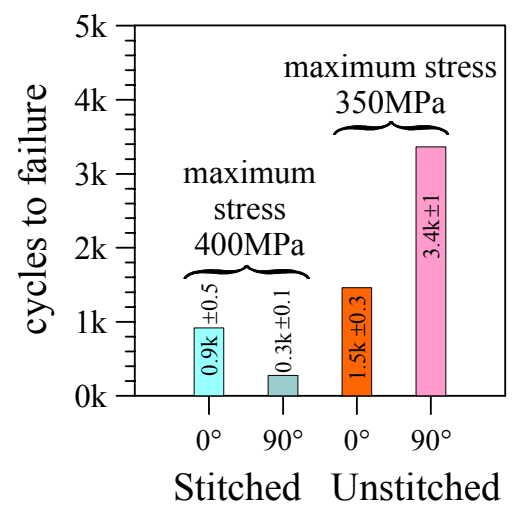

(c)

Figure 8. Average number of cycles to failure for the applied maximum stress levels $( \pm$ means standard deviation). 


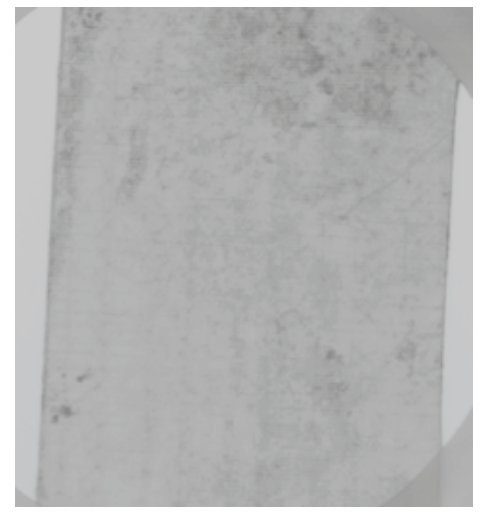

(a)

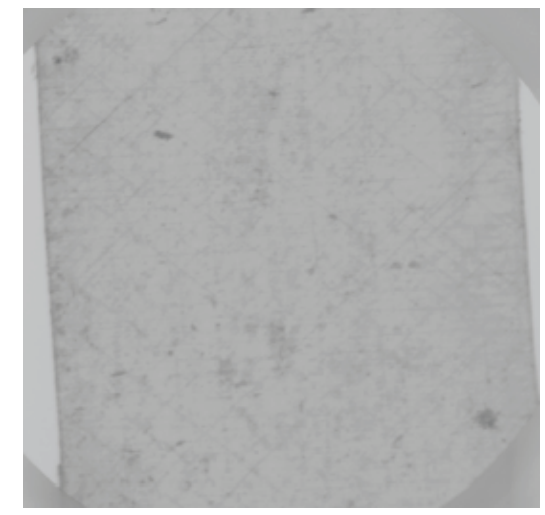

(b)

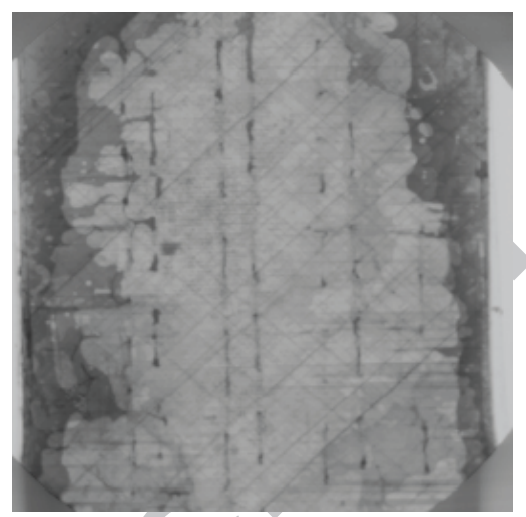

(c)

Figure 9. Typical X-Ray of unstitched specimens after cyclic traction in $0^{\circ}$ direction, maximum stress 240 MPa. Front view of specimens stopped at: (a) 1k; (b) 10k and (c) $100 \mathrm{k}$ cycles.

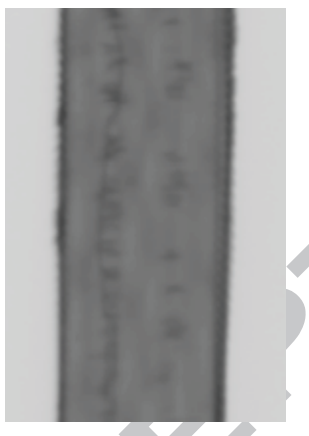

(a)

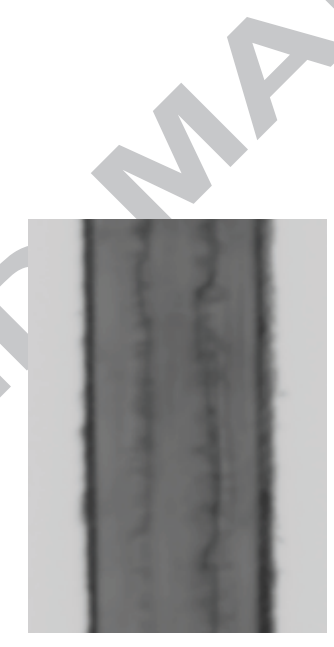

(b)

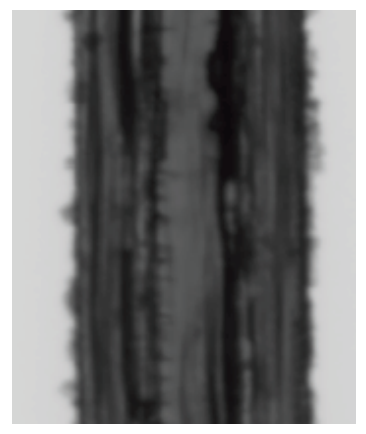

(c)

Figure 10. Typical X-Ray of unstitched specimens after cyclic traction in $0^{\circ}$ direction, maximum stress 240 MPa. Cross-section view of specimens stopped at: (a) 1k; (b) 10k and (c) 100k cycles. 


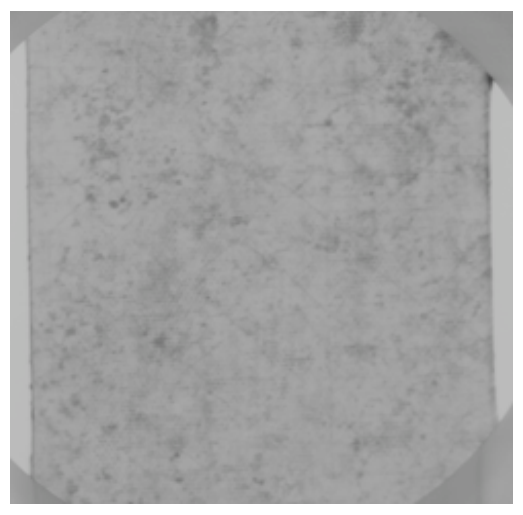

(a)

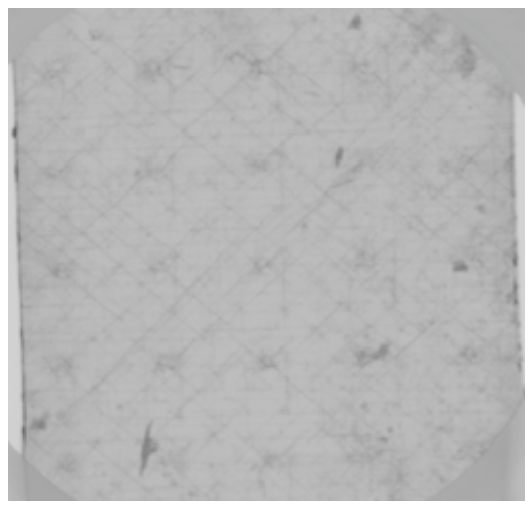

(b)

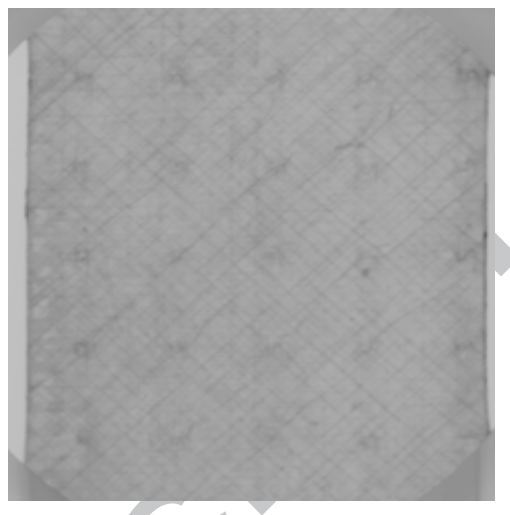

(c)

Figure 11. Typical X-Ray of stitched specimens after cyclic traction in $0^{\circ}$ direction, maximum stress 240 MPa. Front view of specimens stopped at: (a) 1k; (b) 10k and (c) $100 \mathrm{k}$ cycles.

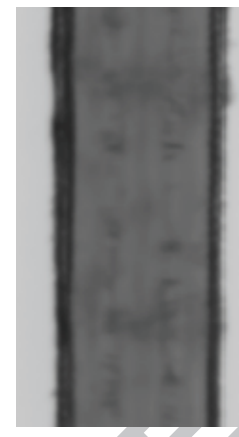

(a)

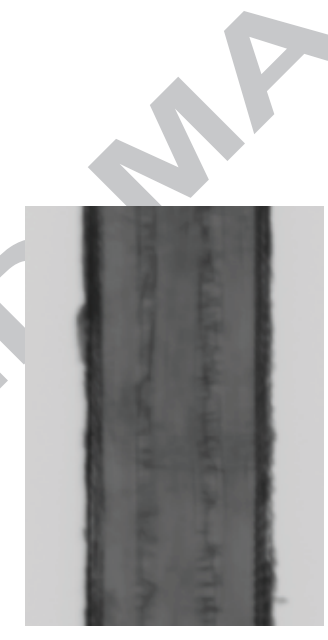

(b)

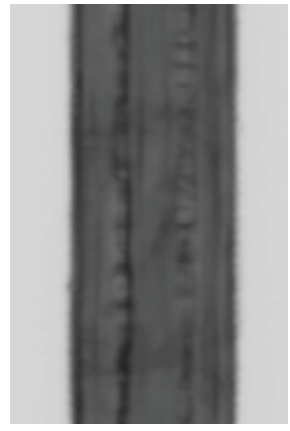

(c)

Figure 12. Typical X-Ray of stitched specimens after cyclic traction in $0^{\circ}$ direction, maximum stress 240 MPa. Cross-section view of specimens stopped at: (a) 1k; (b) 10k and (c) 100k cycles. 


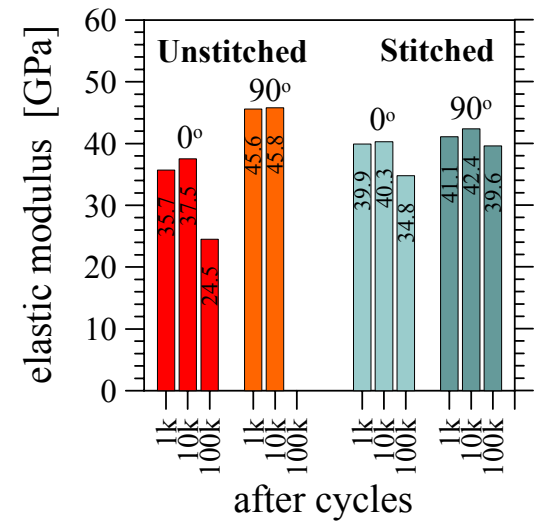

(a)

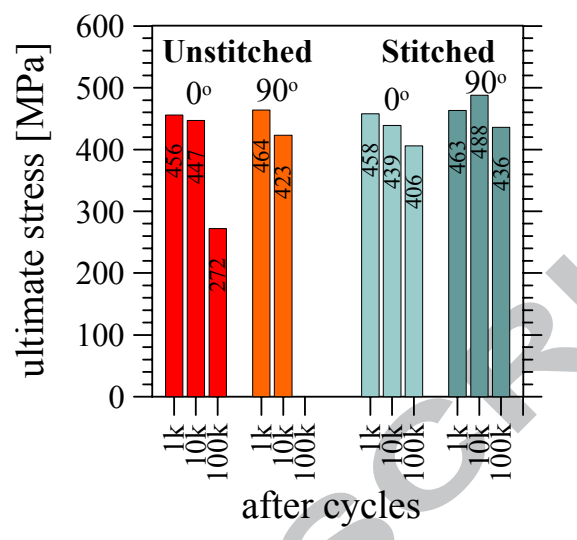

(b)

Figure 13. (a) elastic modulus and (b) ultimate stress of fatigued specimens (maximum stress 240 MPa) after different number of cycles.
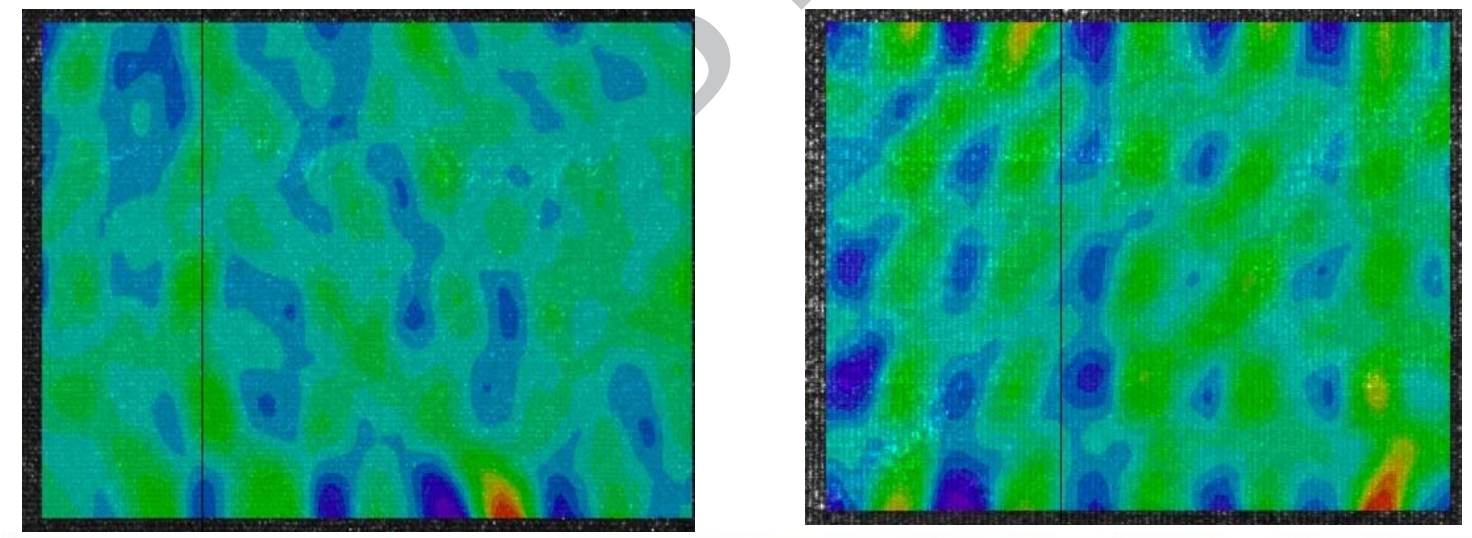

0.0016

(a)

(b)

Figure 14. Mapping of the strain component in the load direction, for stress level $\approx 220 \mathrm{MPa}$. Load direction is horizontal. Specimens of stitched composite in (a) $0^{\circ}$ and (b) $90^{\circ}$ direction after 10.000 cycles with maximum stress 240 MPa. 


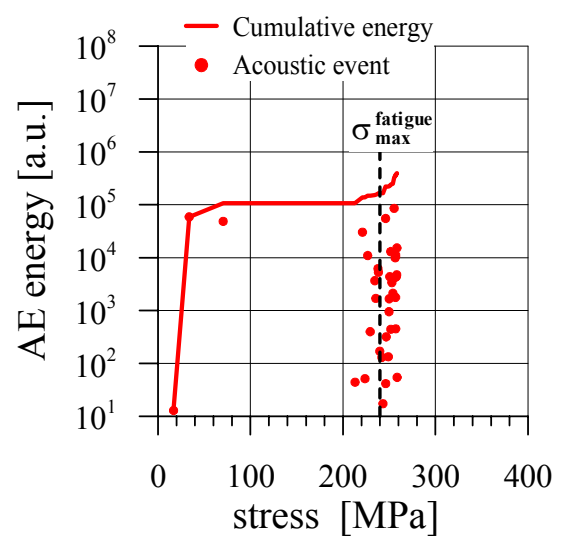

(a)

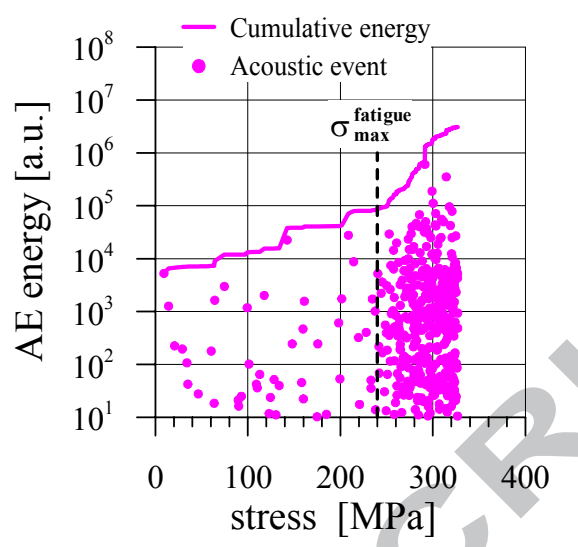

(b)

Figure 15. Unstitched composite: post-fatigue tensile test in $0^{\circ}$ direction after: (a) 1.000 cycles and (b) 10.000 cycles, maximum stress 240 MPa. Acoustic Emission events and cumulative energy ([a.u.] means [arbitrary unit]).

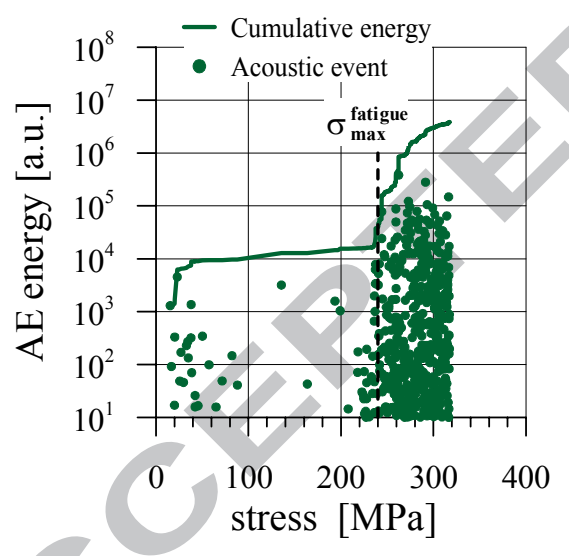

(a)

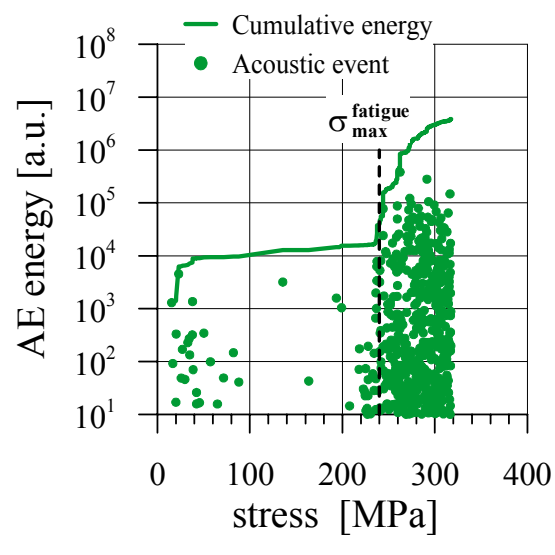

(b)

Figure 16. Stitched composite: post-fatigue tensile test in $0^{\circ}$ direction after: (a) 1.000 cycles and (b) 10.000 cycles, maximum stress 240 MPa. Acoustic Emission events and cumulative energy ([a.u.] means [arbitrary unit]). 


\begin{tabular}{l|c|c|c}
\cline { 2 - 4 } & Tenax ${ }^{\circledR}$ HTS & $\begin{array}{c}\text { Tenax }{ }^{\circledR} \text { HTA } \\
\text { (stitching yarn) }\end{array}$ & $\begin{array}{c}\text { Polyester 83 dtex } \\
\text { SC }\end{array}$ \\
\hline Filament & & 67 & 8,3 \\
Linear Density [Tex] & 800 & 1000 & 12 \\
Number of fibres & 12000 & $\mathrm{~S} 15$ & $\mathrm{Z} 24$ \\
Twisting $\left[\mathrm{m}^{-1}\right]$ & 0 & & \\
\hline Fiber & 7 & 7 & 2,1 \\
Diameter $[\mu \mathrm{m}]$ & 1,77 & 1,76 & 1,38 \\
Density $\left[\mathrm{g} / \mathrm{cm}^{3}\right]$ & \multicolumn{2}{|c}{}
\end{tabular}

Table 1. Some properties of the components (data from Seartex ${ }^{\circledR}$ and Walker Wilhelm GmbH).

\begin{tabular}{lc|ccc}
\hline Maximum Stress [MPa] & $\geq 350$ & 320 & 240 & 200 \\
Frequency $[\mathrm{Hz}]$ & 4 & 4 & 6 & 8 \\
\hline
\end{tabular}

Table 2. Stress levels and frequencies adopted in cyclic loading.

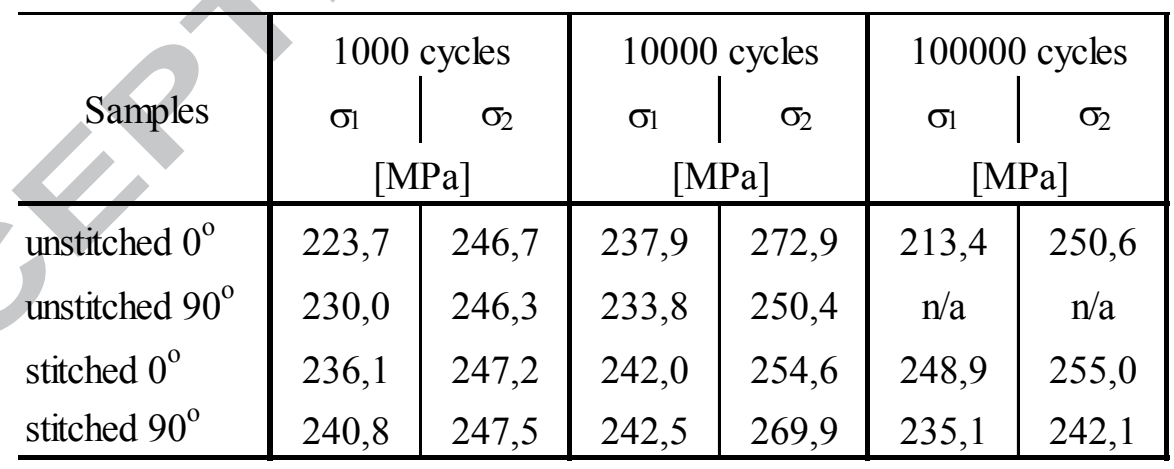

Table 3. Damage threshold $\sigma_{1}$ and $\sigma_{2}$ of fatigued specimens after different number of cycles and maximum stress 240MPa. 